\title{
Current Trends in Clinical Practice for the Minimal Invasive Medial Unicondylar Knee Arthroplasty
}

\author{
Santosh Kumar Sah, Arjun Sinkemani, Yonggang Li* \\ Department of Orthopedic Surgery, Zhongda Hospital, Southeast University School of Medicine, Nanjing, China \\ Email: ^13601454503@163.com
}

How to cite this paper: Sah, S.K., Sinkemani, A. and Li, Y.G. (2020) Current Trends in Clinical Practice for the Minimal Invasive Medial Unicondylar Knee Arthroplasty. Open Journal of Orthopedics, 10, 252267.

https://doi.org/10.4236/ojo.2020.109027

Received: August 21, 2020

Accepted: September 24, 2020

Published: September 27, 2020

Copyright $\odot 2020$ by author(s) and Scientific Research Publishing Inc. This work is licensed under the Creative Commons Attribution International License (CC BY 4.0).

http://creativecommons.org/licenses/by/4.0/

\begin{abstract}
Unicondylar Knee Arthroplasty (UKA) is an early alternative surgical procedure for the unicondylar osteoarthritis or damaged knee joint with artificial prosthesis for the release of disabling painful condition and restoring the normal knee functions. Minimally UKA is one of the recent and the majority successful procedures in modern orthopedics for the osteoarthritis which is spreading throughout the worldwide. Recently, many orthopedic surgeons are expanding their abilities in this field. However, it needs good knowledge and well experience for the successful clinical outcomes. The minimal invasive approach is more efficient for short hospital stay and faster postoperative recovery with low morbidity of the patients after UKA. The aim of this article is to emphasize the steps in UKA based on modern facts: function of knee joint, diagnosis, less invasive approach for medial condylar replacement, radiographic evaluation, and earlier recovery, selecting the patient and implant survivorship with review of surgery.
\end{abstract}

\section{Keywords}

Unicondylar Knee Arthroplasty, Minimal Invasive Knee Arthroplasty, Current Trends of Unicompartmental Knee Arthroplasty

\section{Introduction}

The knee is the most common large joints which are affected by osteoarthritis. In 1950s, the concept of Unicondylar Knee Arthroplasty (UKA) was firstly initiated by MacIntosh and Mckeever, over hemiarthroplasty and useful as metal space maker [inflexible element] in unicondylar knee compartment [1]. Its attractiveness gradually increased superiorly as a minimal invasive approach, as an 
alternative choice to the total knee replacement for the local symptomatic knee osteoarthritis management [2] [3]. St. Georg and Marmor Knee introduced the former current single compartmental device in 1969 and 1972 respectively [4]. The purpose of this procedure was to amplify the post-operative improvement to lessen the hospital stay and speedy recovery to return back to regular daily activities with proper knee function [3]. Initially, the outcomes after this procedure were disagreed due to structure of poly-radial metallic femoral module and a flat tibial module prepared by polyethylene. Wear and polyethylene warp were the major troubles which led to the preamble of metal sustain tibial module. In 1980, Goodfellow, Tibrewal et al. [5], assumed a little dissatisfaction in the earlier materialization in the UKR, as it had suggested itself from weak patient assortment, shortage in prosthetic device development as well as operative procedure. In 1978, O'Connor primarily projected the utilization of a meniscal weight bearing device of knee prosthetic and fixed these designs for bi-compartmental tibio-femoral arthroplasty. The mainstream of modern advancement in UKA is the prospect to employ the arthroplasty utilizing minimum invasive surgical procedure skills. The Knee osteoarthritis frequently affects the medical compartment initially and later it gradually affects the lateral compartment. In its earlier stage, the alternative choices for surgical supervision are unicompartmental arthroplasty, valgus high tibial osteotomy and total knee arthroplasty [6]. Osteoarthritis is the most common reason leading to impairment and functional disability of knee and occurs mostly in elderly patients with simultaneous disruption of Hipknee-ankle load bearing ability. Varus and valgus are strongly related for the increased osteoarthritis, relaying on body mass index, age and sex [7]. Current two surgical approaches are most famous techniques for knee osteoarthritis treatment and both techniques have their own benefits. The principle of High Tibial Osteotomy (HTO) is adjustment of knee misalignment either Varus or valgus. The goal of UKA surgery is to replace the damaged bony surface of the knee. Also, patients who underwent UKA had a better functional outcomes rate than Total Knee Arthroplasty (TKA). The long-term survival rate was low in UKA patients compared to TKA patients. UKA had lower rate due to device type, elevated body mass [obesity], age, unexplained pain, limb alignments, unicondylar implant's location and lack of the surgeon's skills [8].

The minimal invasive approach is capable to provide short hospital stay and postoperative faster recovery with low morbidity of the patients after UKA. The minimal blood loss and blood transfusion requirement, minimum opoids uses, early recovery and minimum complication rate, shorter stay in hospital, advancement in prosthetic design with low costs of implant and highly reassurance of the patient, gradual increasing popularity of surgical procedure, selection of patient and modification in implants variety along with its advantages and greater uses of UKA as minimal invasive process has served as an alternative choice to TKA for the localized degenerative knee osteoarthritis [5] [9] [10] [11] [12]. The aim of this article is to emphasize the steps in UKA based on modern facts: function of knee joint, diagnosis, less invasive approach for medial condy- 
lar replacement, radiographic evaluation, and early recovery, selecting the patient and implant survivorship with review of surgery.

\section{Review of Literatures}

Numerous reviews of the innovative articles were done highlight on current trend in unicompartmental osteoarthritis, minimally invasive unicompartmental knee arthroplasty and unicondylar knee arthroplasty. The articles seek out was done on individual search engine for example RESEARCH GATE, PUBMED, SCOPUS and GOOGLE SCHOLAR (Figure 1).

Approximately 90 articles associated to the knee joint surgery were studied of which 25 articles were extracted which were either related to current trend of UKA, minimally invasive UKA or unicondylar knee arthroplasty. Beyond 25 articles only 8 articles were extracted which were allied to minimal invasive unicondylar knee arthroplasty. Among them 3 articles were excluded as they did not provide exact evidence for current trend in unicondylar knee arthroplasty. Finally, we 5 articles which were focus on clinical trend in minimal invasive UKA, WOMAC and KSS scores.

\section{Function of Knee Joint}

The primary function is to keep up physical strength and walk more efficiently, providing leg stability and proprioception. It plays the role of shock absorber; supports the body in upright position without muscles having to work, helps in lowering and raising body balance especially in climbing, sitting and squatting. It works with the ankle joint as a powerful forward thruster for the body especially when running.

\section{Diagnostic Principle}

The major joints Osteoarthritis is mainly diagnosed in the assortment of medical condition of the body or presenting the symptoms. The diagnosis is performed

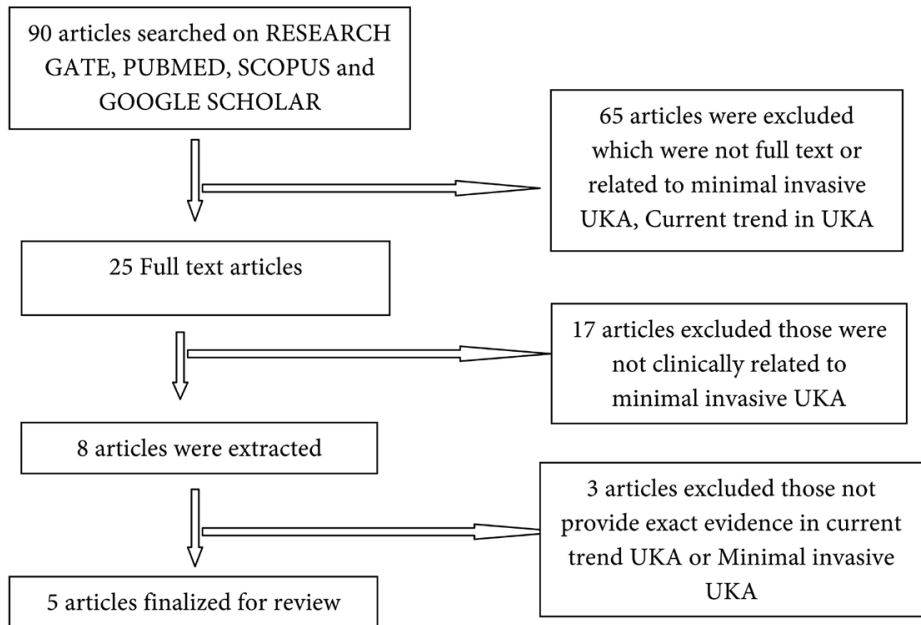

Figure 1. Flowchart showing the articles selection steps in the review. 
by physical assessment, in addition to few special laboratory analyses as well as radiological studies such as X-ray with anteroposterior view Figure 2(a), skyline view Figure 2(c) and lateral view Figure 2(b) illustrates of knee joint. During the evaluation, at some point radiological modalities maybe performed to confirm or to rule out meniscus tear, Anterior Cruciate Ligament (ACL) injury, fracture and degenerative diseases as well as to assess the efficacy of the possible treatment choice.

Traditional proposal and selection criteria for UKA by Kozinn and Scott et al. [1989] [14] [20] [21].

\section{Primary indications \& contraindications}

\begin{tabular}{ll}
\hline \multicolumn{1}{c}{ Indications } & \multicolumn{1}{c}{ Contraindications } \\
\hline $\begin{array}{l}\text { Isolated anteromedial compartment osteoarthritis } \\
\text { disease \& spontaneous osteonecrosis }\end{array}$ & Inflammatory arthritis \\
Cumulative angular deformity $<15^{\circ}$ & Age $<60$ years \\
$\begin{array}{l}\text { Weight }<82 \mathrm{~kg}, \text { Range of motion to } 90^{\circ} \text { of } \\
\text { flexion with no }>5^{\circ} \text { flexion contracture }\end{array}$ & $\begin{array}{l}\text { High activity level, inflammatory } \\
\text { arthropathy }\end{array}$ \\
$\begin{array}{l}\text { No }>10^{\circ} \text { fixed varus malalignment for a } \\
\text { medial arthroplasty }\end{array}$ & Pain at rest and patellofemoral pain \\
$\begin{array}{l}\text { Anterior \& Posterior cruciate ligaments intact } \\
\text { with low physical activities }\end{array}$ & $\begin{array}{l}\text { Opposite compartment pain, } \\
\text { cruciate ligament deficiency }\end{array}$ \\
$\begin{array}{l}\text { Age } \geq 60 \text { years, Preoperative range of flexion } \\
\text { of at least } 90^{\circ}\end{array}$ & $\begin{array}{l}\text { Exposed bone in Patellofemoral } \\
\text { compartment }\end{array}$ \\
\hline
\end{tabular}

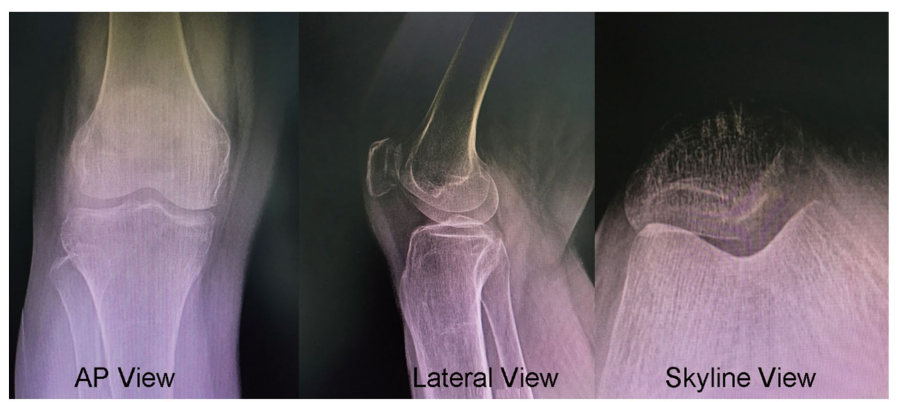

(a)

(b)

(c)

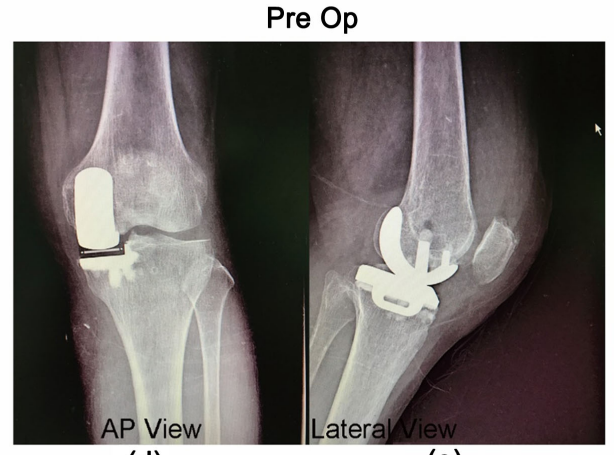

(d)

Post Op

(e)

Figure 2. Source: Zhongda hospital orthopedic department. 
Images of the affected joints can be obtained during radiological examination. There is no cartilage on X-ray film, but the reduction of the knee bone space shows the loss of cartilage. An X-ray also shows bone spurs around the joint as the evidence of osteoarthritis before they experience any symptoms. Magnetic resonance imaging [MRI] uses radio waves of strong magnetic fields to generate bone images and details of surrounding soft tissues including cartilages. An MRI is not necessary for diagnosis of osteoarthritis, but it helps to provide more detailed information in complicated cases [22] [23] [24].

Laboratory test: Evaluation of blood or joint fluid tests can help diagnose and eliminate some additional sources of knee pain, such as rheumatoid arthritis. Fine Needle Aspiration (FNA) is done to extract the joint fluid from the affected joint; then the reason of pain is analyzed and also checked for gout or if the presence of any infection of inflammatory origin [25] [26].

\section{The Step by Step Minimal Invasive Approach for Medial UKA}

The procedure was initiated either under epidural anesthesia or general anesthesia on the customary operation table via both leg receptacles, uses of compression bandage is as per surgeons demands. Now, aseptic draping is done in the customary fashion on 70 degrees angle flexed knee joint, carrying the incision through superficial layer of skin. Incision is carried on until seen the joint capsule and incise the joint capsule parapatellar midline. Incision is made approximately 2 - 3 inches up to higher limit of the patella and extends distally close to the medial side of the tibial tuberosity, however finishing 1 inch below the joint line formerly positioned [27] [28]. A medial arthrotomy is executed as well as the joint is opened. Subsequently medial fat tissue [Fat pad] is excised for well visible of the ACL, femoral condyle as well as corresponding medial tibial plateau Figure 3(a) illustrates. Exploit the medial and lateral retractors for the fine exposure. It's significant to memo that the ideology of ligaments corresponding can be applied to a medial UKA and the collateral ligaments should be neutral or free. The knee is flexed at 60 degree to examine the osteophytes, ACL resistance and Medial Collateral Ligament (MCL) with noting the position of both the patellofemoral joint and lateral compartments [2] [8] [11] [29] [30] [31].

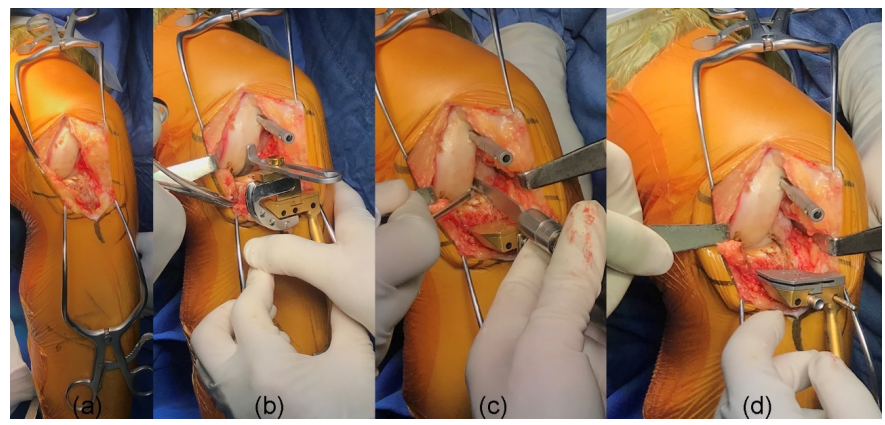

Figure 3. Tibial preparation intraoperative images (a) Inspection ligaments \& osteophytes; (b) Preparation of Tibial cut; (c) Perpendicular cut of Tibia; (d) Horizontal cut. 
[32]. Then remove the over growth osteophytes in the intercondylar notch to circumvent impingement with ACL on the notch Figure 3(b) illustrates. The medial femoral condyle osteophytes should be removed, as these osteophytes will be helpful for the fine positioning the femoral components. In contrast as finishing the perpendicular tibial cut, it's important to recognize plus blot, the anterior touch dot connecting the tibial inhabitant tibial plateau as well as the anterior component of femoral condyle.

\subsection{Tibial Cut}

The three essential aims regarding to the tibial cut associated the applied anatomy of the medial compartment. The perpendicular an extramedullary tibial steer is positioned to evaluate the slope and valgus/varus alignment. Flexed the knee joint up to ninety degrees and the joint incision should be made through an anterior medial arthrotomy preliminary at the medial margin of the patella with finished at $3 \mathrm{~cm}$ underneath the tibia plateau. The opening is deepening during to pierce joint capsule and at proximal end the cut is extensive $1-2 \mathrm{~cm}$ without damaging the Vastus medialis. The primary tibial excision should be least [2 - 4 $\mathrm{mm}$ highest], since the ailment extreme frequently involve the femoral region. It's significant to maintain the deep tibial incision ultraconservative and improve the functional potential of the tibial cortex. Anterior tibia is exposed after the piece of Hoffa's padding is removed. Anterior Cruciate Ligament is scrutinized to see if the UKA prosthetic is appropriate or not. If not; then TKA is appropriate for it. The damaged and over growth osteophytes have been excised as well as the tibial resecting was implemented with an oscillating saw beneath the supervision of a jig, which is located as the anatomical and functional tibial tilt. Firstly, perpendicular incision was implemented subsequently Figure 3(c) illustrates and then the horizontal incision is executed meanwhile the lateral and medial collateral ligaments were preserved by Hohmann retractors Figure 3(d) illustrates. The resection of plateau size releases the gap for a tibial module as well as meniscus component as a minimum $4 \mathrm{~mm}$. The resected plateau scrutinized the advanced reporting flanked by implant and the passion for determining the size of the plateau.

\subsection{Femoral Cut}

The flexion of knee at 45 degrees the hole is willing into intramedullary channel of femur by $5 \mathrm{~mm}$ awl which is located at $1 \mathrm{~cm}$ anterior to antero-medial part of intercondylar indentation. Introduce the intramedullary rod awaiting rod hawker is stopped up opposed to the bone Figure 4(a) illustrates. Applying the femoral drills steers and drill $4 \mathrm{~mm}$ morsel is drilled in the superior outlet into bone up to stop then left in place as the guide. As soon as alignments are established a $6 \mathrm{~mm}$ make a hole in it then drilled throughout the inferior hole in the guide Figure 4(b). When completed, all the instruments from the distal femur are taken out and femoral saw wedge is introduced again in the drilled holes. Subsequently, in these moments some miscellany of osteophytes and medial 


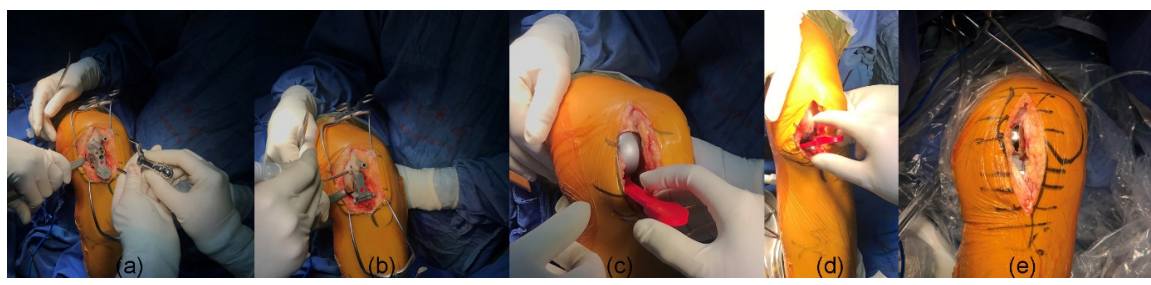

Figure 4. Femoral Preparation, Intraoperative images (a) Femoral guide placed; (b) Femoral cut; (c) Checking stability in flexion; (d) Checking stability in extension; (e) Inserted Implants \& polymer component.

meniscus impingement from the corner of condyle are eliminated. After that 0 $\mathrm{mm}$ spigot was introduced in the main drill hole then the distal portion of the condyle is grinded. The milling depth was decided via balance between flexion and extension adjustment.

Extension and flexion space corresponding was proscribed through analysis of inlays. Posterior and anterior portion of the bone osteophytes resection was desirable to decrease possibility of impingement. After that the tibial plateau was lastly organized. The trials establish the horizontal size of the tibial components. Establish the height of tibial component with femoral component in place then check balance and stability in flexion Figure 4(c) illustrates and extension Figure 4(d) illustrates as well as range of motion and tracking. Drill the holes for femoral and tibial components preparation for the implants. Practice inserting the femoral component a couple of times to make sure it insert easily. Again, try both real implants then remove it and try it again. Start mixing the bone cement and prepare it, inject the bone cement in the tibial holes and thin layer of cement on the tibial surface pre pressurize the cement. Insert the tibial component and pressurized it, the excess bone cement carefully removes from around the implant. Inject the cement in femoral holes and insert the femoral component and pressurized it again. Now pressurized in flexion and extension, again excess cement carefully removes from around the implants and inserts the spacer. Final balances after the cement harden and established polymer component Figure 4(e) illustrates. Make sure that implants surfaces are free from the cement and polymer sits well in its groove. After that incised tissues are closed deep layer to superficial layer respectively.

\section{Indication for Patient Selection and Contraindication for UKA}

Patient assortment is significant paces of the practice for UKA and instruction from the history remain very informative since UKA include several particular modes of failure. The causes of UKA failure were evaluated from our inventive sequence of unicompartmental prosthesis tracked for previous several years. The failure causes loosening of implant, gradually progression of knee osteoarthritis in the replaced compartment and or unreplaced compartment [33] [34] [35]. Rheumatoid arthritis is one of the most contraindication of UKA where it was relatively undiagnosed or relay on over correction of abnormality. Body mal- 
alignment or mal-position of the implant associated with Loosening. Lastly, the majority of the patients modified for polyethylene wear enclosed a novel polyethylene thickness $<8 \mathrm{~mm}$, which is currently recognized designate the lowest thickness to use for smooth polyethylene introduce [32].

Modern criteria of indication \& contraindication for UKA [9] [36].

\begin{tabular}{cll}
\hline & \multicolumn{1}{c}{ Indications } & \multicolumn{1}{c}{ contraindication } \\
\hline $\mathbf{1}$ & Presence of arthritis within patellofemoral joint & Inflammatory arthropathy, \\
$\mathbf{2}$ & Having chondrocalcinosis & Ligamentous instability, \\
$\mathbf{3}$ & $\begin{array}{l}\text { Don't strictly exclude patients based on age, } \\
\text { weight, activity level }\end{array}$ & Contracture of the MCL, \\
$\mathbf{4}$ & Highly active patients & Functionally absent ACL, \\
$\mathbf{5}$ & Younger $\geq 45$ years and older [ $\geq 75$ years] & Previous high tibial osteotomy \\
$\mathbf{6}$ & $\begin{array}{l}\text { ACL deficient patient without instability by } \\
\text { decreasing posterior slop of tibial component. }\end{array}$ & \\
\hline
\end{tabular}

\subsection{Clinical Evaluation}

The clinical assessment needs to ensure a minimum range of motion of 90 degrees of perioperative flexion, and to insert the femoral prosthetic components through a small incision. Patellofemoral joints is also necessary for experimental assessment to support the expression of some unexplained anterior knee pain in daily activities such as stair hiking, downhill and crouching patients [23] [33] [37] [38]. It is of great significance to evaluate the stability and strength of the anterior and posterior cruciate ligament evaluating via Lachman test, pivot shift test, anterior and posterior drawer test and the condition of the collateral ligaments [32]. The single chamber implants bind the space preserved by the damaged cartilage, and pull the collateral ligament to the natural pressure after the end of the action process. The clinical outcomes of UKA via movable meniscus approach plus in vivo motion assessment of patients with tibial horizontal fixation bearings show the significance of a purposeful ACL for single condylar knee replacement [1] [3] [35] [39] [40].

\subsection{Radiological Evaluation}

Utilization of the MRI, CT-scan contains potential to localize the radiological pattern of disease and supportive guidance to precision or pre-operative arthroscopy has specific consign during our clinical sense choice to achieve UKA [22] [23] [41]. Conversely, the ultimate judgment might be used in various case intra-operative assessments of the conflicting section plus tender grip on the ACL. Most of case utilize complete load bearing outlooks the extremity in bipodal or unipodal posture. This observational assess the overall tibio-femoral viewpoint with measurement of the angle among femoral anatomical axis and extremity perfunctory alliance to brief potential to the distal femoral incise [9] [33]. It will power to estimate whichever extra-articular skeletal abnormality, which can't be approved via Unicondylar implant moreover investigate in favor of femoral hip stem and required the utilization of a short intra-medullary fe- 
moral rod [42] [43] [44]. The stress analysis executes in varus for the medical compartment and utilized to confirm the indication of Unicondylar substitution with full cartilage thickness loss in the medial exaggerated compartment. In valgus, stress vision confirms the total thickness of cartilage in the unchanged lateral compartment with complete rectification of the anomaly to normal. In the event of incomplete or excessive modification, the visualization of stress will indicate the absence of collateral balance of the ligament, and then the total replacement of the knee is performed [32]. The lateral view of the joint will corroborate the anterior deficiency of tibial conversion $>10 \mathrm{~mm}$ referring to the posterior boundary of the tibial plateau and will demonstrate that tibial erosion is inadequate for the frontal and middle segments of the tibial plateau [13] [24] [29]. Axial patellofemoral inspections will authenticate the adequate cartilage thickness of the patellofemoral joint. The incidence of osteophytes peri-patella may not be a contraindication for unicondylar replacement that can still be highlighted by minimal incision. Some authors claim that patellofemoral joint is not a model of adequacy and some authors state that complete loss of patellofemoral cartilage is currently contraindication to unicondylar replacement performance [7] [42] [45].

\subsection{Current Trends}

The patient's expectations for knee replacement surgery have changed through the main surgical pathway strengthening, enhancement in the implants design, multiple pain strategies, enhanced surgical techniques and the implementation of the same-day surgery program. Ensuring a simpler, faster functioning and faster recovery activation process, primarily for isolated knee compartment osteoarthritis [46], can lead to a significant increase in UKA frequency. At present, some additional indicators have been extended to achieve excellent clinical results [7] [36] [37] [38] [39] [44] [47] [48]. Long-term supervision provides an extension of the encouragement of the implants currently available and the continued existence of surgery, and the published statistics suggest that the use of Ambulatory Surgical Centers (ASCs) is safe and effective for same-day surgery. In recent, the Medicare centers and Medicaid Services has denoted UKA as an outpatient technique as well as provide adequate indications for hospitalization for more than 23 hours [49] [50]. The increased the survival rate and reduce the revision rate in minimal invasive UKA can be contributed as the good improvement of knowledge and well experience of surgeon for the well defined patient selection criteria, enhancement in surgical technology, approach and enhancement of implants designs. The survivorship rates are comparable to individuals achieved with a typical open approach but the functional outcomes are better in minimal invasive UKA.

Complications:

Numerous authors have inveterate the admirable radiologic and clinical outcomes and survival rate of minimal invasive UKA as mention on Table 1 and Table 2 respectively. However malalignment, pain, instability, stress fracture of 
Table 1. UKA Prosthesis-specific design survivorship\% based on implant failures resulting in revision surgery at time of study reported follow-up: Historical UKA prosthesis design survivorship overview [1] [4] [5] [13] [14] [15] [16].

\begin{tabular}{ccccccc}
\hline Author/Study [years] & Numbers & Survivorship & Follow up & Prosthesis design & Study design & Results \\
\hline MacIntosh et al. [1972] & 130 & $95 \%$ & 7 Years & MacIntosh vitallum & Prospective & $\begin{array}{c}\text { Good clinical outcomes at } \\
\text { short term follow up }\end{array}$ \\
$\begin{array}{c}\text { Mackinnon \& } \\
\text { Mamor } \text { et al. [1988] }\end{array}$ & 39 & $95 \%$ & 5 Years & St. Georg Sled & Retrospective & Better functional outcomes \\
Kozinn \& & 100 & $90 \%$ & 25 Years & & & Good clinical outcomes at \\
Scott et al. [1989, 1991] & & $90 \%$ & 9 Years & & years follow up \\
Squire \& & 140 & $84 \%$ & 11 Years & Unicondylar knee & Prospective & Clinically and survival \\
rates are better
\end{tabular}

Table 2. Historical oxford knee UKA survivorship overview [5] [17] [18] [19].

\begin{tabular}{|c|c|c|c|c|c|}
\hline Authors/Years & Number & $\begin{array}{l}\text { Oxford } \\
\text { Knee }\end{array}$ & $\begin{array}{l}\text { Follow } \\
\text { up }\end{array}$ & Survivorship & Results \\
\hline $\begin{array}{l}\text { Edmondson } \\
\text { et al. [2015] }\end{array}$ & 364 & Phase 3 & 10 Years & $95 \%$ & $\begin{array}{l}\text { Better clinical functions and } \\
\text { survival at } 10 \text { years. }\end{array}$ \\
\hline $\begin{array}{l}\text { Yoshida } \\
\text { et al. [2013] }\end{array}$ & 1279 & Phase 3 & 10 Years & $95 \%$ & $\begin{array}{l}\text { Clinical outcomes are better } \\
\text { with } 10 \text { years follow up }\end{array}$ \\
\hline $\begin{array}{c}\text { Faour } \\
\text { et al. }[2013]\end{array}$ & 511 & Phase 3 & 10 Years & $96 \%$ & $\begin{array}{l}\text { Clinical outcomes are better } \\
\text { than standard open approach. }\end{array}$ \\
\hline $\begin{array}{l}\text { Murray } \\
\text { et al. [1998] }\end{array}$ & 143 & Phase $1 \& 2$ & 8 Years & $97 \%$ & $\begin{array}{l}\text { Excellent clinical outcomes } \\
\text { in the midterm follow up. }\end{array}$ \\
\hline $\begin{array}{l}\text { Robertsson } \\
\text { et al. [1995] }\end{array}$ & 663 & Phase $1,2 \& 3$ & 20 Years & $92 \%$ & $\begin{array}{l}\text { Better functional outcomes } \\
\text { and few revision to TKA }\end{array}$ \\
\hline $\begin{array}{l}\text { Goodfellow \& } \\
\text { O’Connor } \\
\text { et al. [1988] }\end{array}$ & 103 & Phase $1 \& 2$ & 10 Years & $98 \%$ & $\begin{array}{l}\text { Excellent functional } \\
\text { satisfaction in the } \\
\text { survival rate. }\end{array}$ \\
\hline
\end{tabular}

medial tibial plateau, meniscal dislocation, and unexplained pain, loosening of femoral component or osteoarthritis of lateral compartment appeared as the post operative complications. In 2016, Van der list et al. reported osteoarthritis progression and aseptic loosening as the main complication of UKA [46] [51].

\subsection{The Knee Scoring Systems}

There are several scoring systems developed for the assessment of outcome of knee after UKA such as the joint-specific Western Ontario and McMaster Universities (WOMAC) osteoarthritis index and Knee Society Score (KSS). The 
WOMAC Index is commonly used index for the assessment of knee which was introduced by Bellamy et al. [52]. The WOMAC score contain pain scores, stiffness scores and function scores. Where this score presents a subjective assessment of the knee. The WOMAC questionnaire is extensively applied for evaluating knee OA. This score has been measured as good index for OA assessment [53]. These scores contain 24 questionnaires which are separated into 3 fragments: 5 questions for pain, 2 questions for stiffness, and 17 questions for function. The WOMAC score consist of $0-100$ scale. The outcome is specified as an arithmetic standard of the significant questions. Outcome range from 0 100 , whereas 0 specify no pain, stiffness, and functional limitation and 100 specify the severe painful, highly stiffness, and strictly limited function.

Another one is the Knee Society Score [KSS] is also extensively applied in scoring system for assessment after UKA/TKA. The KSS consist of the knee scores and also function scores [54] [55]. Judgment of the knee joint itself for knee pain, range of motion and strength is completed via the knee scores. The functional scores assist to evaluate the patient's ability to walk and to climb stairs, utilize of ambulatory supports. The score is support on the $75 \%$ of subjective plus $25 \%$ objective measurement.

Hospital for Special Surgery Knee score [HSS] [20] is another form of evaluation which contains of Knee Pain, range of motion, function of the knee, muscle strength, flexion deformity, and instability and subtraction apparatus. HSS contains questionnaires as 100 points at full mark, with best condition equaling 100 points [Excellent $\geq 85$, Good $=70-84$, Fair $=60-69$, Poor $\leq 60$ ]. Based on this criteria, the studied by Zhou Xinhua et al. [56], the HSS knee score was enhanced from $50.33 \pm 11.60$ to $90.06 \pm 3.07$ [P $<0.001$ ], representing good outcome subsequent UKA.

\section{Conclusion}

Current trends in clinical practice as minimal invasive approach have significant advantages and are capable to provide shorter hospital stay and rapid postoperative recovery with low morbidity of the patients after UKA. Improvement of pain scores, early recovery, and improvement in better knee functions with better quality of life evaluated more in the last few years which had positioned minimally invasive UKA like the typical choice of management in unicondylar knee osteoarthritis. However, some authors are still criticizing and enhancing for long term outcomes and survivorship of implants. In other hand, some important factors such as mechanical alignment, body mass index poor preoperative functions and surgeon's skills also impact on the postoperative functions. In this review paper, we conclude that the combination of early recovery and different evaluations more in the last few years into patient collection with minimal operative guidelines have positioned Unicondylar Arthroplasty, like the typical choice management in favor of patient in the course of knee osteoarthritis controlled toward the single tibio-femoral compartment is very important. 


\section{Acknowledgements}

We would like to thank Dr. Wei Jinan, from Department of Orthopedics, Zhongda Hospital, Southeast University, China for his warm support and coordination. Further we express our gratitude towards Mulmi Shrestha Sachin from School of Medicine, Southeast University, China for his valuable guidance.

\section{Conflicts of Interest}

The authors have no conflict of interest relevant to this article.

\section{References}

[1] Macintosh, D.L. (1958) Hemiarthroplasty of the Knee Using Space Occupying Prosthesis for Painful Varus and Valgus Deformities. Journal of Bone and Joint Surgery, 40, 1431 .

[2] Brown, N., Sheth, N., Davis, K., Berend, M., Lombardi, A., Berend, K., et al. (2012) Total Knee Arthroplasty Has Higher Postoperative Morbidity than Unicompartmental Knee Arthroplasty: A Multicenter Analysis. The Journal of Arthroplasty, 27, 86-90. https://doi.org/10.1016/j.arth.2012.03.022

[3] Peersman, G., Jak, W., Vandenlangenbergh, T., Jans, C., Cartier, P. and Fennema, P. (2014) Cost-Effectiveness of Unicondylar versus Total Knee Arthroplasty: A Markov Model Analysis. The Knee, 21, S37-S42. https://doi.org/10.1016/S0968-0160(14)50008-7

[4] Marmor, L. (1988) Unicompartmental Knee Arthroplasty: Ten- to 13-Year Follow-Up Study. Clinical Orthopaedics and Related Research, 226, 14-20. https://doi.org/10.1097/00003086-198801000-00004

[5] Goodfellow, J.W., Kershaw, C.J., Benson, M.K. and O'Connor, J.J. (1988) The Oxford Knee for Unicompartmental Osteoarthritis. The First 103 Cases. The Journal of Bone and Joint Surgery. British Volume, 70, 692-701. https://doi.org/10.1302/0301-620X.70B5.3192563

[6] Ahlback, S. (1968) Osteoarthrosis of the Knee. A Radiographic Investigation. Acta Radiologica: Diagnosis, 277, 7-72.

[7] Sharma, L., Song, J., Felson, D.T., Cahue, S., Shamiyeh, E. and Dunlop, D.D. (2001) The Role of Knee Alignment in Disease Progression and Functional Decline in Knee Osteoarthritis. JAMA, 286, 188-195. https://doi.org/10.1001/jama.286.2.188

[8] Asada, S., Inoue, S., Tsukamoto, I., Mori, S. and Akagi, M. (2019) Obliquity of Tibial Component after Unicompartmental Knee Arthroplasty. Knee, 26, 410-415. https://doi.org/10.1016/j.knee.2018.12.013

[9] Rodríguez-Merchán, E.C. and Gómez-Cardero, P. (2018) Unicompartmental Knee Arthroplasty: Current Indications, Technical Issues and Results. EFORT Open Reviews, 3, 363-373. https://doi.org/10.1302/2058-5241.3.170048

[10] Repicci, J.A. and Eberle, R.W. (1999) Minimally Invasive Surgical Technique for Unicondylar Knee Arthroplasty. Journal of the Southern Orthopaedic Association, 8, 20-27.

[11] Jenny, J.Y. (2018) Minimally Invasive Unicompartmental Knee Arthroplasty. European Journal of Orthopaedic Surgery \& Traumatology, 28, 793-797. https://doi.org/10.1007/s00590-017-2107-5

[12] Murray, D.W. and Parkinson, R.W. (2018) Usage of Unicompartmental Knee Arthroplasty. The Bone \& Joint Journal, 100-B, 432-435. 
https://doi.org/10.1302/0301-620X.100B4.BJJ-2017-0716.R1

[13] Pandit, H., Gulati, A., Jenkins, C., Barker, K., Price, A.J., Dodd, C.A., et al. (2011) Unicompartmental Knee Replacement for Patients with Partial Thickness Cartilage Loss in the Affected Compartment. Knee, 18, 168-171.

https://doi.org/10.1016/j.knee.2010.05.003

[14] Kozinn, S.C. and Scott, R. (1989) Unicondylar Knee Arthroplasty. The Journal of Bone and Joint Surgery American Volume, 71, 145-150. https://doi.org/10.2106/00004623-198971010-00023

[15] Berger, R.A. and Della Valle, C.J. (2010) Unicompartmental Knee Arthroplasty: Indications, Techniques, and Results. Instructional Course Lectures, 59, 47-56. https://doi.org/10.1142/9789814282048 0023

[16] MacIntosh, D.L. and Hunter, G.A. (1972) The Use of the Hemiarthroplasty Prosthesis for Advanced Osteoarthritis and Rheumatoid Arthritis of the Knee. Journal of Bone and Joint Surgery-Series B, 54, 244-255. https://doi.org/10.1302/0301-620X.54B2.244

[17] Yoshida, K., Tada, M., Yoshida, H., Takei, S., Fukuoka, S. and Nakamura, H. (2013) Oxford Phase 3 Unicompartmental Knee Arthroplasty in Japan-Clinical Results in Greater than One Thousand Cases over Ten Years. The Journal of Arthroplasty, 28, 168-171. https://doi.org/10.1016/j.arth.2013.08.019

[18] Edmondson, M., Atrey, A., East, D., Ellens, N., Miles, K., Goddard, R., et al. (2015) Survival Analysis and Functional Outcome of the Oxford Unicompartmental Knee Replacement up to 11 Years Follow up at a District General Hospital. Journal of Orthopaedics, 12, S105-S110. https://doi.org/10.1016/j.jor.2013.12.007

[19] Faour-Martín, O., Valverde-García, J.A., Martín-Ferrero, M.Á., Vega-Castrillo, A., de la Red Gallego, M.A., Suárez de Puga, C.C., et al. (2013) Oxford Phase 3 Unicondylar Knee Arthroplasty through a Minimally Invasive Approach: Long-Term Results. International Orthopaedics, 37, 833-838. https://doi.org/10.1007/s00264-013-1830-8

[20] Kon, E., Altadonna, G., Filardo, G., Matteo, B.D. and Marcacci, M. (2014) Knee Scoring Systems. In: Bentley, G., Ed., European Surgical Orthopaedics and Traumatology: The EFORT Textbook, Springer, Berlin, 3371-3388. https://doi.org/10.1007/978-3-642-34746-7 120

[21] Kellgren, J.H. and Lawrence, J.S. (1957) Radiological Assessment of Osteo-Arthrosis. Annals of the Rheumatic Diseases, 16, 494-502. https://doi.org/10.1136/ard.16.4.494

[22] Sowers, M., Karvonen-Gutierrez, C.A., Jacobson, J.A., Jiang, Y. and Yosef, M. (2011) Associations of Anatomical Measures from MRI with Radiographically Defined Knee Osteoarthritis Score, Pain, and Physical Functioning. The Journal of Bone and Joint Surgery American, 93, 241-251. https://doi.org/10.2106/JBJS.I.00667

[23] Petersson, I.F., Boegard, T., Saxne, T., Silman, A.J. and Svensson, B. (1997) Radiographic Osteoarthritis of the Knee Classified by the Ahlback and Kellgren \& Lawrence Systems for the Tibiofemoral Joint in People Aged 35-54 Years with Chronic Knee Pain. Annals of the Rheumatic Diseases, 56, 493-496.

https://doi.org/10.1136/ard.56.8.493

[24] Mullaji, A.B., Sharma, A. and Marawar, S. (2007) Unicompartmental Knee Arthroplasty: Functional Recovery and Radiographic Results with a Minimally Invasive Technique. The Journal of Arthroplasty, 22, 7-11. https://doi.org/10.1016/j.arth.2006.12.109

[25] Elson, C.J., Thompson, S.J., Westacott, C.I. and Bhoola, K.D. (1992) Update Mediators of Joint Swelling and Damage in Rheumatoid Arthritis and Pristane Induced 
Arthritis. Autoimmunity, 13, 327-331. https://doi.org/10.3109/08916939209112342

[26] Martel-Pelletier, J. (2004) Pathophysiology of Osteoarthritis. Osteoarthritis and Cartilage, 12, 31-33. https://doi.org/10.1016/j.joca.2003.10.002

[27] Tria, A.J. and Scuderi, G.R. (2015) Minimally Invasive Knee Arthroplasty: An Overview. World Journal of Orthopedics, 6, 804-811. https://doi.org/10.5312/wjo.v6.i10.804

[28] Berger, R.A. and Hartzband, M.A. (2004) Minimally Invasive Total Hip Arthroplasty: The Two-Incision Approach. In: Scuderi, G.R. and Tria, A.J., Eds., MIS of the Hip and the Knee: A Clinical Perspective, Springer, New York, 7-31. https://doi.org/10.1007/0-387-21715-0 2

[29] Pang, H.N., Ee, G., Lo, N.N. and Yeo, S.J. (2012) Minimally Invasive Unicondylar Knee Arthroplasty in a Patellectomized Patient. Knee Surgery, Sports Traumatology, Arthroscopy, 20, 1831-1833. https://doi.org/10.1007/s00167-011-1787-3

[30] Ollivier, M., Abdel, M.P., Parratte, S. and Argenson, J.-N. (2014) Lateral Unicondylar Knee Arthroplasty (UKA): Contemporary Indications, Surgical Technique, and Results. International Orthopaedics, 38, 449-455. https://doi.org/10.1007/s00264-013-2222-9

[31] Fisher, N., Agarwal, M., Reuben, S.F., Johnson, D.S. and Turner, P.G. (2006) Sporting and Physical Activity Following Oxford Medial Unicompartmental Knee Arthroplasty. The Knee, 13, 296-300. https://doi.org/10.1016/j.knee.2006.03.004

[32] Argenson, J.-N. and Flecher, X. (2004) Minimally Invasive Unicompartmental Knee Arthroplasty. The Knee, 11, 341-347. https://doi.org/10.1016/j.knee.2003.12.002

[33] Suter, L., Roth, A., Angst, M., von Knoch, F., Preiss, S., List, R., et al. (2019) Is ACL Deficiency Always a Contraindication for Medial UKA? Kinematic and Kinetic Analysis of Implanted and Contralateral Knees. Gait Posture, 68, 244-251. https://doi.org/10.1016/j.gaitpost.2018.11.031

[34] Robertsson, O., Knutson, K., Lewold, S. and Lidgren, L. (2001) The Routine of Surgical Management Reduces Failure after Unicompartmental Knee Arthroplasty. The Journal of Bone and Joint Surgery. British Volume, 83, 45-49. https://doi.org/10.1302/0301-620X.83B1.0830045

[35] Ode, Q., Gaillard, R., Batailler, C., Herry, Y., Neyret, P., Servien, E., et al. (2018) Fewer Complications after UKA than TKA in Patients over 85 Years of Age: A CaseControl Study. Orthopaedics \& Traumatology. Surgery \& Research, 104, 955-999. https://doi.org/10.1016/j.otsr.2018.02.015

[36] Kuwashima, U., Okazaki, K., Tashiro, Y., Mizu-Uchi, H., Hamai, S., Okamoto, S., et al. (2015) Correction of Coronal Alignment Correlates with Reconstruction of Joint Height in Unicompartmental Knee Arthroplasty. Bone \& Joint Research, 4, 128133. https://doi.org/10.1302/2046-3758.48.2000416

[37] Thambiah, M., Tan, M. and Hui, J. (2017) Role of High Tibial Osteotomy in Cartilage Regeneration-Is Correction of Malalignment Mandatory for Success? Indian Journal of Orthopaedics, 51, 588-599.

https://doi.org/10.4103/ortho.IJOrtho $260 \quad 17$

[38] Oosthuizen, C., Straeten, C., Maposa, I., Snyckers, C., Vermaak, D. and Magobotha, S. (2019) The Patient Results and Satisfaction of Knee Arthroplasty in a Validated Grading System. International Orthopaedics, 43, 2747-2755. https://doi.org/10.1007/s00264-019-04412-z

[39] Meneghini, R.M., Ziemba-Davis, M., Ishmael, M.K., Kuzma, A.L. and Caccavallo, P. (2017) Safe Selection of Outpatient Joint Arthroplasty Patients with Medical Risk Stratification: The "Outpatient Arthroplasty Risk Assessment Score". Journal of Arth- 
roplasty, 32, 2325-2331. https://doi.org/10.1016/j.arth.2017.03.004

[40] Matsui, Y., Fukuoka, S., Masuda, S., Matsuura, M., Masada, T. and Fukunaga, K. (2019) Accuracy of Tibial Component Placement in Unicompartmental Knee Arthroplasty Performed Using an Accelerometer-Based Portable Navigation System. Knee Surgery, Sports Traumatology, Arthroscopy. https://doi.org/10.1007/s00167-019-05752-4

[41] Pelletier, J.P., Cooper, C., Peterfy, C., Reginster, J.Y., Brandi, M.L., Bruyere, O., et al. (2013) What Is the Predictive Value of MRI for the Occurrence of Knee Replacement Surgery in Knee Osteoarthritis? Annals of the Rheumatic Diseases, 72, 1594 1604. https://doi.org/10.1136/annrheumdis-2013-203631

[42] Yue, J., Zhang, L. and Yang, C. (2015) The Impact of Patellofemoral Arthritis on Unicompartmental Knee Arthroplasty. Acta Orthopaedica Belgica, 81, 587-593.

[43] Ventura, A., Legnani, C., Terzaghi, C., Iori, S. and Borgo, E. (2017) Medial Unicondylar Knee Arthroplasty Combined to Anterior Cruciate Ligament Reconstruction. Knee Surgery, Sports Traumatology, Arthroscopy, 25, 675-680. https://doi.org/10.1007/s00167-015-3808-0

[44] Ridgeway, S.R., et al. (2002) The Effect of Alignment of the Knee on the Outcome of Unicompartmental Knee Replacement. The Journal of Bone and Joint Surgery British Volume, 84-B, 351-355. https://doi.org/10.1302/0301-620X.84B3.0840351

[45] Saccomanni, B. (2010) Unicompartmental Knee Arthroplasty: A Review of Literature. Clinical Rheumatology, 29, 339-346.

https://doi.org/10.1007/s10067-009-1354-1

[46] van der List, J.P., Kleeblad, L.J., Zuiderbaan, H.A. and Pearle, A.D. (2017) MidTerm Outcomes of Metal-Backed Unicompartmental Knee Arthroplasty Show Superiority to All-Polyethylene Unicompartmental and Total Knee Arthroplasty. HSS Journal: The Musculoskeletal Journal of Hospital for Special Surgery, 13, 232-240. https://doi.org/10.1007/s11420-017-9557-5

[47] Kort, N.P., Bemelmans, Y.F.L. and Schotanus, M.G.M. (2017) Outpatient Surgery for Unicompartmental Knee Arthroplasty Is Effective and Safe. Knee Surgery, Sports Traumatology, Arthroscopy, 25, 2659-2667. https://doi.org/10.1007/s00167-015-3680-y

[48] Broughton, N.S., Newman, J.H. and Baily, R.A. (1986) Unicompartmental Replacement and High Tibial Osteotomy for Osteoarthritis of the Knee. A Comparative Study after 5-10 Years' Follow-Up. The Journal of Bone and Joint Surgery. British Volume, 68, 447-452. https://doi.org/10.1302/0301-620X.68B3.3733813

[49] Cody, J.P., Pfefferle, K.J., Ammeen, D.J. and Fricka, K.B. (2018) Is Outpatient Unicompartmental Knee Arthroplasty Safe to Perform at an Ambulatory Surgery Center? A Comparative Study of Early Post-Operative Complications. Journal of Arthroplasty, 33, 673-676. https://doi.org/10.1016/j.arth.2017.10.007

[50] Baker, P., Jameson, S., Critchley, R., Reed, M., Gregg, P. and Deehan, D. (2013) Center and Surgeon Volume Influence the Revision Rate Following Unicondylar Knee Replacement: An Analysis of 23,400 Medial Cemented Unicondylar Knee Replacements. The Journal of Bone and Joint Surgery American Volume, 95, 702-709. https://doi.org/10.2106/JBJS.L.00520

[51] van der List, J.P., Zuiderbaan, H.A. and Pearle, A.D. (2016) Why Do Medial Unicompartmental Knee Arthroplasties Fail Today? Journal of Arthroplasty, 31, 1016 1021. https://doi.org/10.1016/j.arth.2015.11.030

[52] Bellamy, N., Buchanan, W.W., Goldsmith, C.H., Campbell, J. and Stitt, L.W. (1988) Validation Study of WOMAC: A Health Status Instrument for Measuring Clinically 
Important Patient Relevant Outcomes to Antirheumatic Drug Therapy in Patients with Osteoarthritis of the Hip or Knee. The Journal of Rheumatology, 15, 18331840.

[53] Bellamy, N. (2002) WOMAC: A 20-Year Experiential Review of a Patient-Centered Self-Reported Health Status Questionnaire. The Journal of Rheumatology, 29, 24732476.

[54] Insall, J.N., Dorr, L.D., Scott, R.D. and Scott, W.N. (1989) Rationale of the Knee Society Clinical Rating System. Clinical Orthopaedics and Related Research, 248, 13-14. https://doi.org/10.1097/00003086-198911000-00004

[55] Scuderi, G.R., Bourne, R.B., Noble, P.C., Benjamin, J.B., Lonner, J.H. and Scott, W.N. (2012) The New Knee Society Knee Scoring System. Clinical Orthopaedics and Related Research, 470, 3-19. https://doi.org/10.1007/s11999-011-2135-0

[56] Zhou, X., Wang, M., Liu, C., Zhang, L. and Zhou, Y. (2014) Total Knee Arthroplasty for Severe Valgus Knee Deformity. Chinese Medical Journal, 127, 1062-1066.

\section{Abbreviations}

UKA: Unicondylar Knee Arthroplasty

ACL: Anterior Cruciate Ligament

MCL: Medial Collateral Ligament

TKA: Total Knee Arthroplasty

HTO: High Tibial Osteotomy

ASC: Ambulatory Surgical Center 